\title{
MORPHOLOGICAL, CHEMICAL CHARACTERS AND GENETIC ANALYSIS DISCRIMINATION OF FIVE NATURALIZED POPULUS SPECIES INHABITING FOUR GOVERNORATE TERRITORIES OF EGYPT
}

\author{
Ahmed ${ }^{1}$ M.F., Hosni ${ }^{2}$ A.M., Hewidy ${ }^{\star}$ M., Abd El razik ${ }^{1}$ A.B. \\ and Bahnasy ${ }^{3}$ M.I. \\ 1- Genetic. Dept., Fac. of Agric., Ain Shams Univ., P.O. Box 68, Hadayek Shobra 11241, Cairo, \\ Egypt \\ 2- Hortic. Dept., Fac. of Agric., Ain Shams Univ., P.O. Box 68, Hadayek Shobra 11241, Cairo, \\ Egypt \\ 3- Forestry and Timber Tree Research Dept., Hortic. Res. Inst., Agric. Res. Center, Giza, Egypt \\ *Corresponding author: mohamed.hewidy@agr.asu.ed.eg
}

Received 7 October, 2019

Accepted 12 November, 2019

\begin{abstract}
Populus is a fast growing tree that attract the attention of people. This genus provides environment protection due to their ability in carbon sequestration, phytoremediation and wildlife inhabitant. Populus species are widely used as a source of wood, veneer, paper and bioenergy. This survey study aimed to identify the current status of Populus species inhabiting four different governorates of the Egyptian territories. In this survey, four different locations were surveyed, i.e. Cairo, Giza, Qaliobia and Gharbia governorates. According to the site survey, five species of Populus were found. Research findings indicate that the length and diameter of the trees varied according to various species in various localities. Selected trees of various species were subjected to different morphological, chemical parameters and genetic assessments. $P$. deltoides from Giza in addition to $P$. deltoides and $P$. nigra from Cairo gave somewhat close relation in their vegetative parameters. Furthermore, both $P$. nigra and $P$. alba from Gharbia location gave high similarity due to overall vegetative parameters and also both $P$. euramericana female from the Gharbia and $P$. nigra from Qaliobia. Genetic diversity was analyzed using molecular markers. Three different Inter-simple sequence repeat (ISSR) primers were used for the reaction (17899A, 17899B and HB13). ISSR primers markers yielded $67.5 \%$ polymorphic loci among the surveyed species and cluster analysis enabled separation of these populations on the basis of their genetic distances. $P$.
\end{abstract}

euramericana female and male from Giza showed close relation at morphological level. From this study it can be concluded that: firstly; leaf parameters i.e. leaf area width and length were suitable for identifying the differences among species, and secondly; genetic analysis using molecular markers was enough to discriminate between species. Our results finally suggest that Populus species possess genetic variation and can adapt to new environmental conditions, which in its self-valuable information would potentially lead to promising applications.

Keywords: Egypt, Survey study, Woody trees, Poplar, Populus, Morphology, Genetic analysis, ISSR

\section{INTRODUCTION}

Poplar (Populus spp.) is regarded as a group of species growing all over the world. Due to its fastgrowing feature and acceptable quality of timber; it plays significant roles in silviculture. Therefore, paying attention to its characteristics along with gathering more information on it can enable us to apply and treat correctly. To our knowledge no survey was conducted up till now on the importance of popular trees diversity and various morphological and biometric analyses in Egypt.

Plant surveys are designed to search in geographic areas to determine the presence of exotic species, like Populus amongst other species and evaluate its their habitat suitability (Haber and Network, 1997). 
Poplar include 33 species belonging to the family Salicaceae. The poplar species are native to North America. The wood of poplars is relatively soft and hence is mostly used to make cardboard boxes, crates, paper, and veneer (Isebrands \& Richardson, 2000)

Some Populations of Populus face severe threats. Three main factors have been recognized. The first one is the alteration of riparian ecosystems throughout the species' distribution area. Second, faster growing hybrid poplars have been planted to replace black poplar or they have just been removed due to over-exploitation. Finally, there is the potential threat of introgression from cultivated poplars such as the male clone 'Italica' (Cagelli and Lefèvre 1995, Lefèvre et al 1998).

Leaf morphology may offer precise differentiation because it varies remarkably among species and within species with respect to structure, dimensions, types of margins, form, size of petiole, venation pattern, dry weight per unit area, moisture content, canopy, stomata density, presence of trichomes and cuticular composition (Rodriguez et al 2016).

Interesting enough, genetic discrimination analyses using various techniques, i.e. AFLP or
ISSR represent rather new insight for curious differentiation among species (Bandyopadhyay et al 2013). Inter simple sequence repeat (ISSR) requires very small amount of template and is convenient in result recording and highly reproducible (Zietkiewicz et al 1994).

Accordingly, the aim of this study was to conduct basic research to identify and find out similarities and differences amongst Populus species surveyed at the morphological, chemical and genetic levels.

\section{MATERIAL AND METHODS}

\section{Location and duration}

A rapid reconnaissance survey was carried out at four research stations belonging to the Agriculture Research Center at four different governorates of Egypt, viz. Cairo, Giza, Qaliobia and Gharbia. Survey result data in Table (1) demonstrate the presence of five species of Populus at the Horticulture Research Stations, located in four governorates from which plant material were collected in June and August of 2016.

Table 1. Naturalized Populus species at research stations in four governorates of Egypt

\begin{tabular}{|c|c|c|}
\hline Governorate & Research Station & Populus species \\
\hline Giza & Horticulture research institute & $\begin{array}{c}\text { Populus euramericana }+ \\
\text { P. euramericana } \delta \\
\text { P. deltoides }\end{array}$ \\
\hline Cairo & Zohria garden & P. nigra \\
\hline Qaliobia & $\begin{array}{l}\text { Horticulture research station in } \\
\text { Qanater }\end{array}$ & P. nigra \\
\hline Gharbia & $\begin{array}{l}\text { Agriculture research station in } \\
\text { Gemiza }\end{array}$ & $\begin{array}{c}\text { P. nigra } \\
\text { P. deltoides } \\
\text { P. alba } \\
\text { P. euramericana } 9\end{array}$ \\
\hline
\end{tabular}

\section{Data collected}

\section{Morphological characteristics}

- Tree height was estimated with the use of a clinometer.

- Tree diameter at Breast Height (DBH), i.e. the stem diameter measured in $\mathrm{cm}$ at $1.5 \mathrm{~m}$ above ground level. Number of branches along the main trunk were counted.
- Number of branches.

- Leaf area, width and length of leaf, they were estimated selecting completely grown leaves from the middle of branches. Leaves were photographed using a digital camera as presented in Plate (1) then resulted photos were elaborated using Image J program (Schneider et al., 2012) which calculated individual leaf area, width and length. 

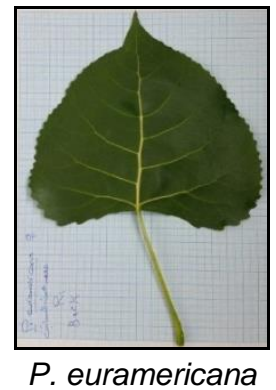

female - Giza

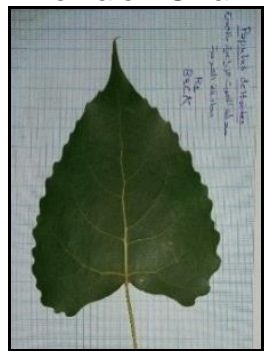

P. deltoides Gharbia
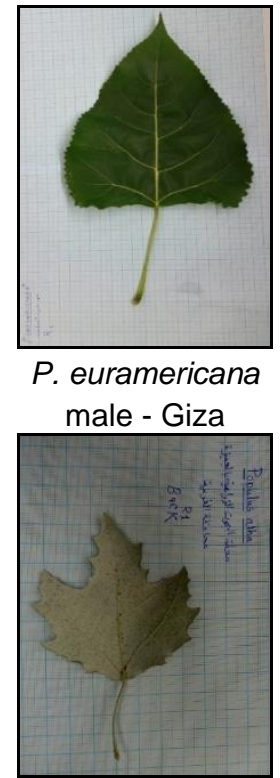

P. alba -

Gharbia

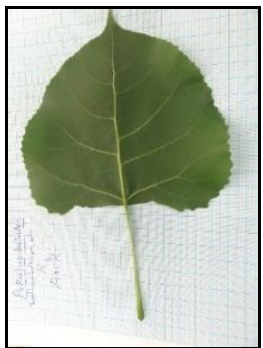

P. deltoides -

Giza

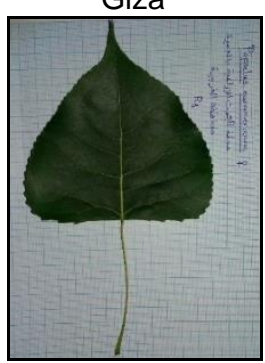

$P$. euramericana female - Gharbia

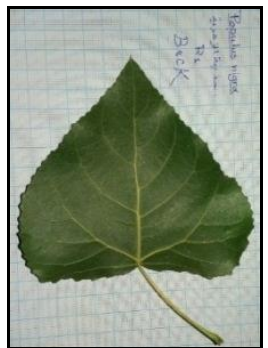

P. nigra Cairo

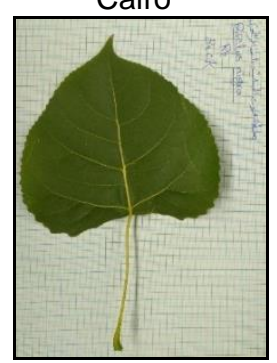

P. nigra -

Qaliobia

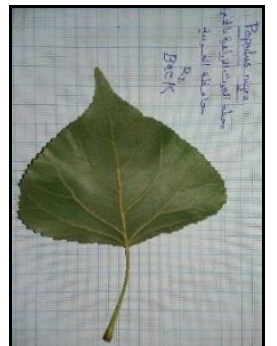

P. nigra-

Gharbia

Plate 1. Photographed mature leaves of surveyed Populus species from four governorates in Egypt, viz. Giza, Cairo, Qaliobia and Gharbia in June-August 2016

- Leaf fresh and dry weight, 20 leaves were collected then weight to obtain fresh weight then oven-dried at $70{ }^{\circ} \mathrm{C}$ to estimate dry biomass.

- Leaf greenness was estimated using SPAD.

\section{Internal chemical analysis}

The content of $\mathrm{N}, \mathrm{P}, \mathrm{K}, \mathrm{Ca}$ and $\mathrm{Mg}$ elements were determined in oven dried samples of leaves by digestion using concentrated $\mathrm{H}_{2} \mathrm{SO}_{4}$. $\mathrm{N}$ percentage was determined in the digested solution by the modified microkjeldahl method as described by Plummer (1971). P percentage was determined calorimetrically according to the method of Jackson (1958). K percentage was determined against a standard using a flame photometer (Piper, 1950). Ca and Mg percentage was determined by an atomic absorption spectrophotometer, according to David (1959).

\section{DNA Extraction}

DNA extraction was applied for the nine different treatments of Populus plant. DNA extraction followed CTAB method according to Doyle and Doyle (1990) and modified by Edwards et al (1991).

\section{Molecular Marker Bioassay Analysis (ISSR)}

The ISSR molecular marker was applied to calculate the variation in Populus plant (Meyer et al 1993). Three different ISSR primers were used for the reaction (17899A, 17899B and HB13) as described in Table 2.

\section{Statistical Analysis}

Survey data were statistically analyzed according to the separation among means using Duncan multiple range test (Duncan, 1995). To identify the relation between each individual characteristic of various Populus species, the correlation was analyzed using the CoStat.

Image results from electrophoresis were analyzed by the presence of a band which scored as 1 , whereas the absence of the band was coded as 0 . A pair wise similarity matrix was generated using Jaccard's similarity coefficient and using the unweighted pair group method with the arithmetic averaging algorithm (UPGMA), cluster analysis was performed to develop a dendrogram. These calculations were carried out using Bio-Rad Quantity one (4.6.2) as prescribed by Li et al (2008). 
Table 2. List of primer names (ID) utilized, their nucleotide sequences in the ISSR analysis

\begin{tabular}{|c|c|l|c|c|}
\hline No & Primer name & Primers nucleotide sequence & GC\% & $\begin{array}{c}\text { Temperature } \\
\left({ }^{\circ} \mathbf{C}\right)\end{array}$ \\
\hline $\mathbf{1}$ & $17899 \mathrm{~A}$ & 5'-CACACACACACAAG-3' & 50 & 42 \\
$\mathbf{2}$ & $17899 \mathrm{~B}$ & 5'-CACACACACACAGG-3' & 57.1 & 50 \\
$\mathbf{3}$ & HB13 & 5'-GAGGAGGAGGC-3' & 72.7 & 38 \\
\hline
\end{tabular}

\section{RESULTS}

\section{Morphological parameters}

Morphological parameters were demonstrated in Fig. 1. Diameter of trees at breast height (DBH) showed significant variation among different species. $P$. deltoides and $P$. euramericana female Giza and $P$. deltoides from Gharbia gave the largest $\mathrm{DBH}$ (54.1, 49.1 and $48.4 \mathrm{~cm}$, respectively). Whereas, the lowest $\mathrm{DBH}$ were obtained from $P$. euramericana female in Gharbia and $P$. nigra in Qaliobia (22.3 and $25.5 \mathrm{~cm}$, respectively). Number of tree branches on different species were varied, the highest value was found in both $P$. euramericana female from Giza and $P$. nigra from Cairo (9.8 and 9 branches/ tree, respctively). Whereas, $P$. euramericana female from Gharbia showed the lowest number of branches (3 branches). As far as tree height was concerned, $P$. nigra from Cairo and $P$. euramericana female from Giza showed the tallest height among different species surveyed (17 and $16.33 \mathrm{~m}$, respectively). Whereas, $P$. euramericana female from Gharbia showed the lowest value of tree height $(6 \mathrm{~m})$. Average of leaf area (LA) showed variation among species. Both female and male of $P$. euramericana from Giza were superior in their leaf area/leaf $\left(225\right.$ and $210 \mathrm{~cm}^{2} /$ leaf, respectively). Whereas, the smallest leaf area was found in $P$. alba from Gharbia (35 $\mathrm{cm}^{2} /$ leaf). Linearly with LA leaf width and length showed similar trend. Both female and male of $P$. euramericana from Giza were superior in their leaf width and length $(25.38 \times 17.20 \mathrm{~cm}$ and $28.7 \times 17.4 \mathrm{~cm})$. Whereas, the smallest value was found in $P$. alba from Gharbia $(11.8 \times 7.6 \mathrm{~cm})$. The fresh and dry weight of collected leaf samples showed relative variation among the surveyed species in different governorates. The highest fresh and dry weight was found in $P$. euramericana male from Giza (3.6 and $1.2 \mathrm{~g} /$ leaf). Whereas, the lowest fresh weight was found in $P$. alba from Gharbia (1 g/leaf), in respect order and lowest dry weight was found in $P$. nigra from Cairo ( $0.4 \mathrm{~g} / \mathrm{leaf})$.

\section{Greenness of leaves}

SPAD readings in Fig. 2 recorded highest value in the $P$. alba from Gharbia governorate (53.35). $P$ nigra plants in surveyed governorates gave close insignificant values (44.65, 45.90 and 47.70) in Qaliobia, Cairo and Gharbia, respectively). Moreover, results obtained in case $P$. deltoides and $P$. euramericana male and female were more or less equal with lowest values regardless of governorate location (refer to Fig. 2).

\section{Leaves Chemical Analysis}

$\mathrm{N}, \mathrm{P}$ and $\mathrm{K} \%$ concentrations, in leaf samples of Popolus species surveyed are shown in Figure 2. The amount of $\mathrm{N}$ averaged $2 \%$ in sampled leaves and the highest \% of $\mathrm{N}$ was found in $P$. nigra from Qaliobia governorate (2.27\%). Whereas, the lowest $\mathrm{N} \%$ was found in $P$. nigra from Gharbia $(1.67 \%)$. The amount of $P$ ranged from 0.15 to $0.55 \%$ in leaf samples. $P$ showed higher percentage for all species in Gharbia governorate $(0.51$, $0.48,0.48$ and $0.58 \%$ in $P$. deltoides, $P$. euramericana female, $P$. alba and $P$. nigra, respectively) when compared to the other species in other three governorates surveyed. The amount of $\mathrm{K}$ was between $0.6-1.1 \%$ in sampled leaves. Without any significant difference among surveyed species in all governorate locations. $\mathrm{Mg}$ and $\mathrm{Ca}$ elements showed similar trends in which the lowest values ( 0.169 and 0.114 , respectively) were obtained from species $P$. euramericana female and $P$. alba grown in Gharbia governorate and showed higher percentage in Giza governorate $P$. euramericana male (0.528 and 1,07 , respectively). 

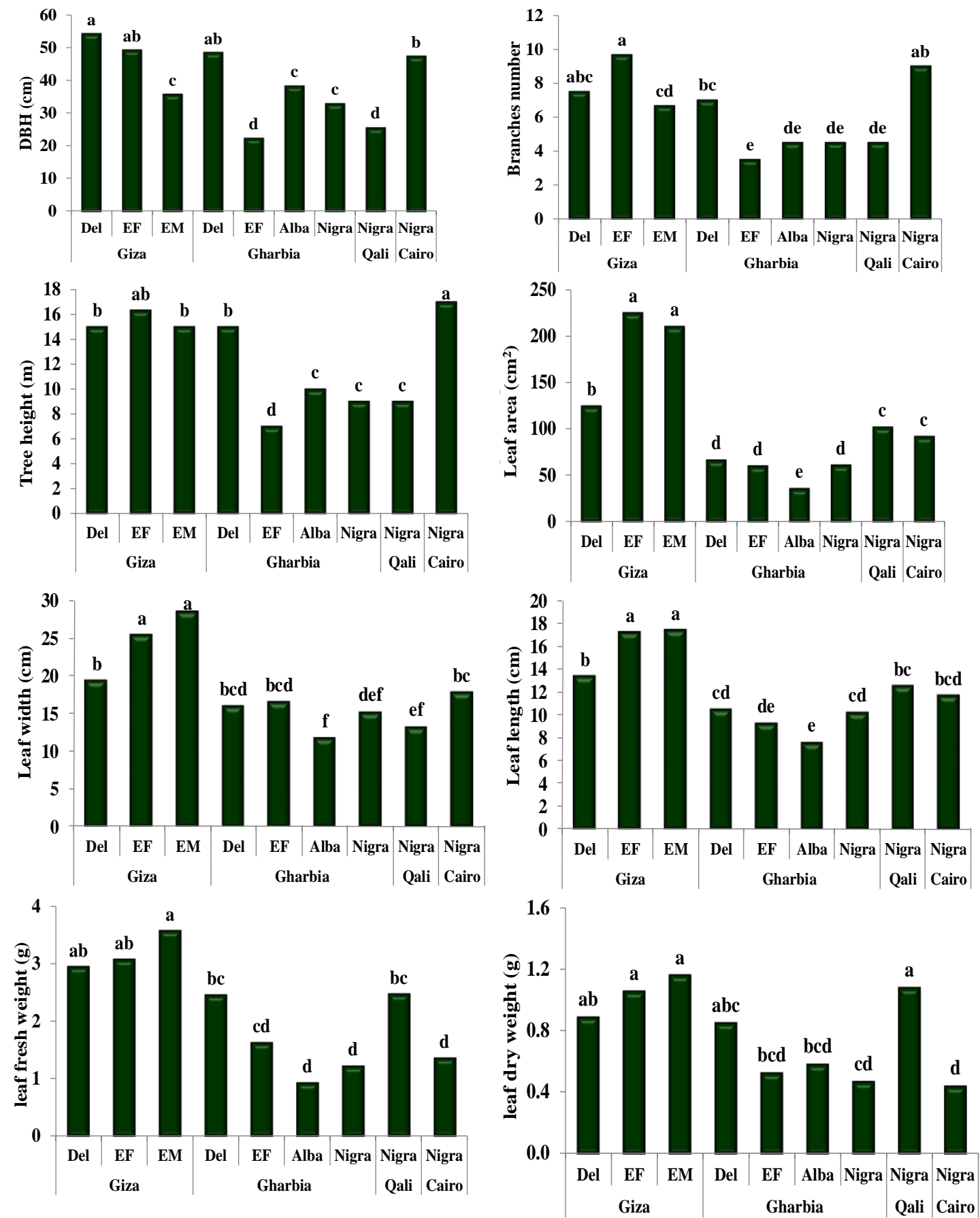

Fig. 1. Vegetative parameters of different surveyed Populus species in four governorates of Egypt. Abbreviations: Del: $P$. deltoides, EF: $P$. euramericana female, EM: $P$. euramericana male, Alba: $P$. alba, Nigra: P. nigra, Qali: Qaliobia. 


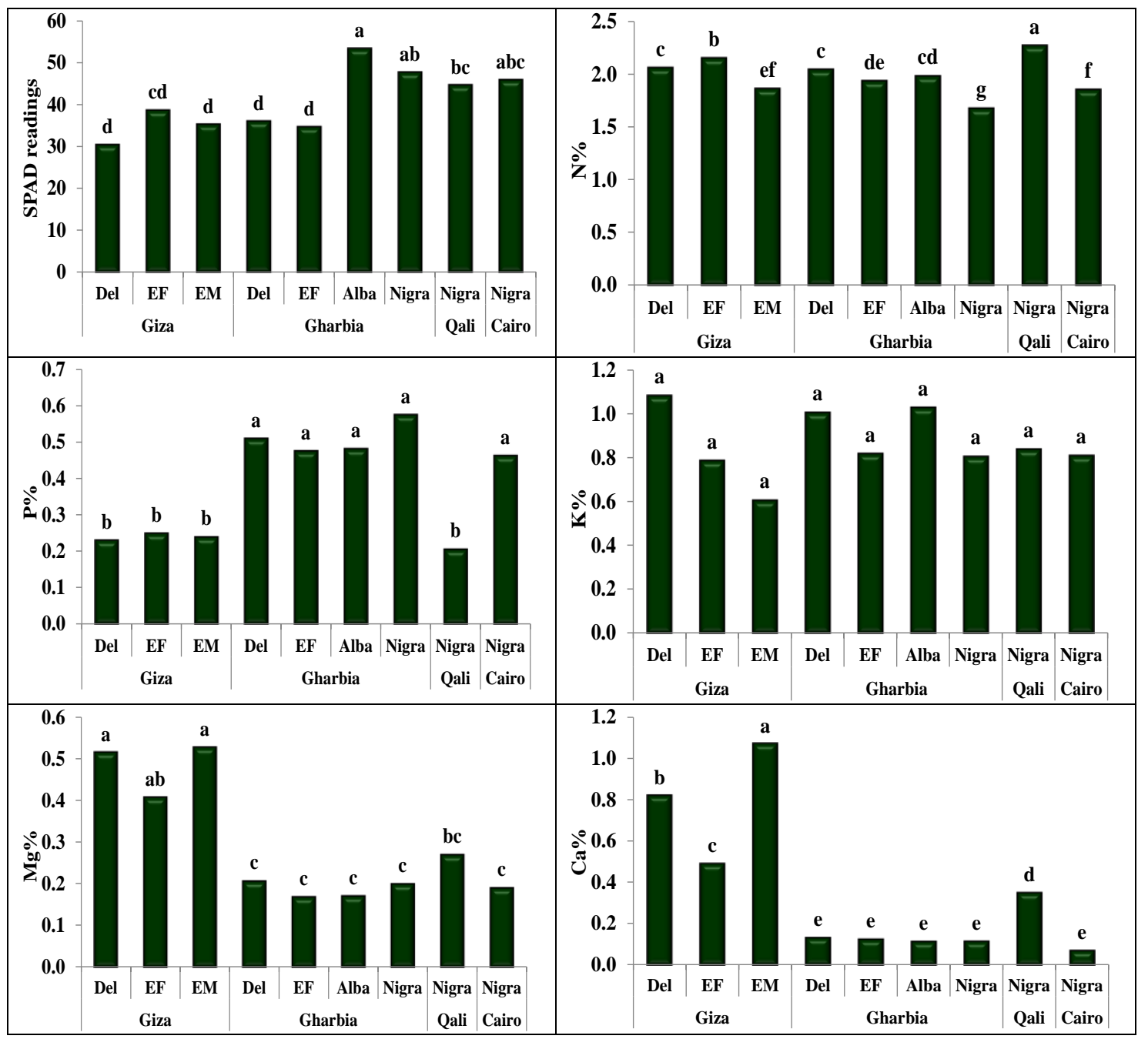

Fig. 2. Internal chemical content of $\mathrm{N}, \mathrm{P}, \mathrm{K}, \mathrm{Mg}$ and $\mathrm{Ca}$ and greenness colour of leaves SPAD value in sampled leaves of different surveyed Populus species in four governorates of Egypt.

Abbreviations: Del: $P$. deltoides, EF: $P$. euramericana female, EM: $P$. euramericana male, Alba: $P$. alba, Nigra: $P$. nigra, Qali: Qaliobia.

According to the coefficients of correlation, the relation among the examined morphometric and chemical characters varied (Table 3). DBH and number of branches were significantly correlated with the increase in tree height. A high correlation was found also among length of the leaf blade, width of the leaf blade and leaf area suggesting that these characters share similar info and each could be an indicator for the same information about the difference amongst populations. The increase in $\mathrm{Ca}$ content was positively correlated with various leaf parameters. The $\mathrm{P} \%$ showed negative correlation with leaf parameters and $\mathrm{N} \%$.
Leaves dry weight also negatively correlated with Mg content and SPAD value.

Neighbor-joining clustering trees constructed from available morphological and chemical analysis data showed the relation among different studied species (Plate 2). $P$. euramericana female and male from Giza showed close relation at morphological level. In addition, $P$. deltoides from Giza, $P$. deltoides and $P$. nigra from Cairo gave high similarity. Furthermore, both $P$. nigra and $P$. alba from Gharbia gave high similarity as was also both $P$. euramericana female from Gharbia and $P$. nigra from Qaliobia. 


\begin{tabular}{|c|c|}
\hline $\bar{\Omega}$ & 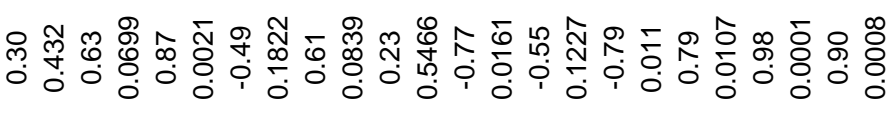 \\
\hline | & 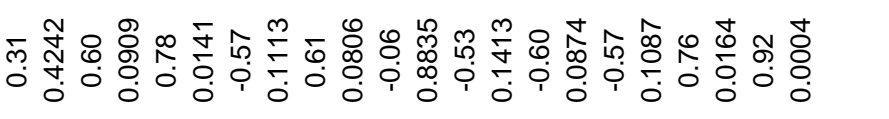 \\
\hline 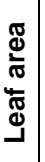 & 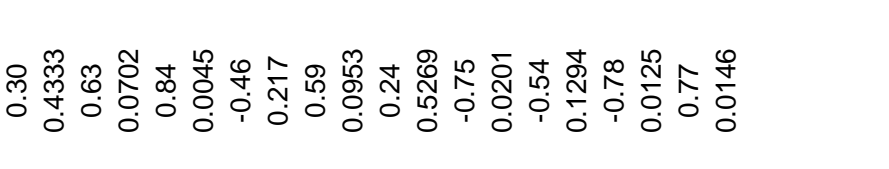 \\
\hline ठ̊ํ & 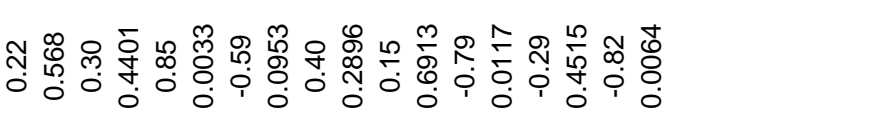 \\
\hline ஃ̊ำ & 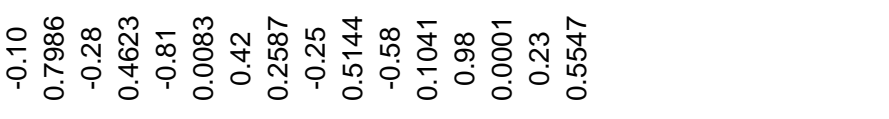 \\
\hline ஓे & 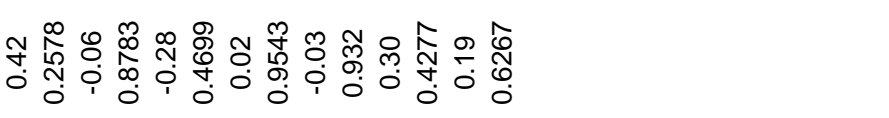 \\
\hline$\stackrel{\circ}{\circ}$ & 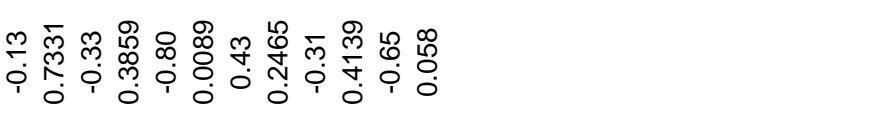 \\
\hline$\stackrel{\circ}{\mathbf{z}}$ & 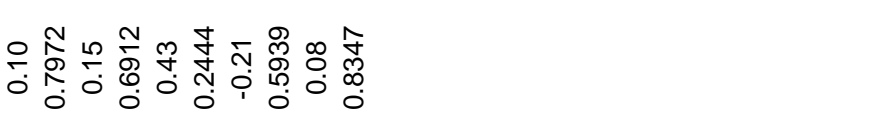 \\
\hline 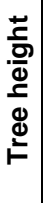 & 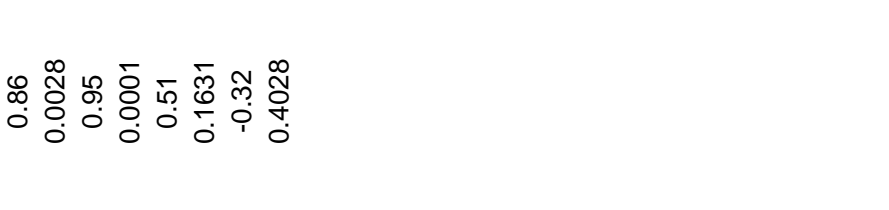 \\
\hline $\begin{array}{l}\frac{q}{a} \\
\text { क }\end{array}$ & 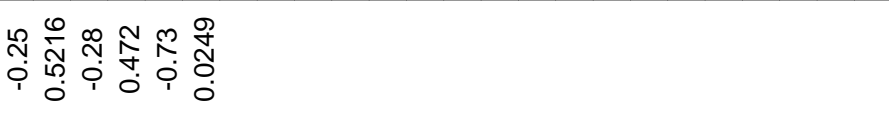 \\
\hline בุ & 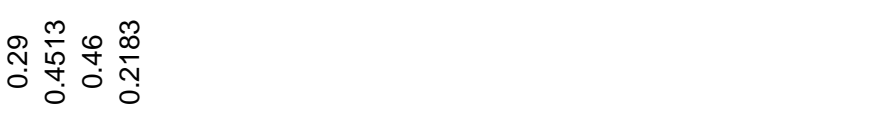 \\
\hline Ф & 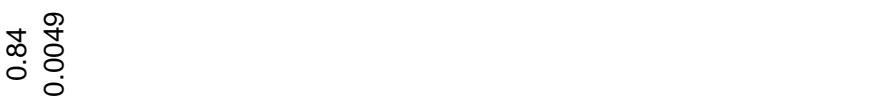 \\
\hline & I I \\
\hline
\end{tabular}




\begin{tabular}{lllll}
\hline $3.97 \mathrm{E} 4$ & $1.71 \mathrm{E} 4$ & 7.47E3 & $3.9 \cdot 2.41 .00 \mathrm{E} 3$
\end{tabular}

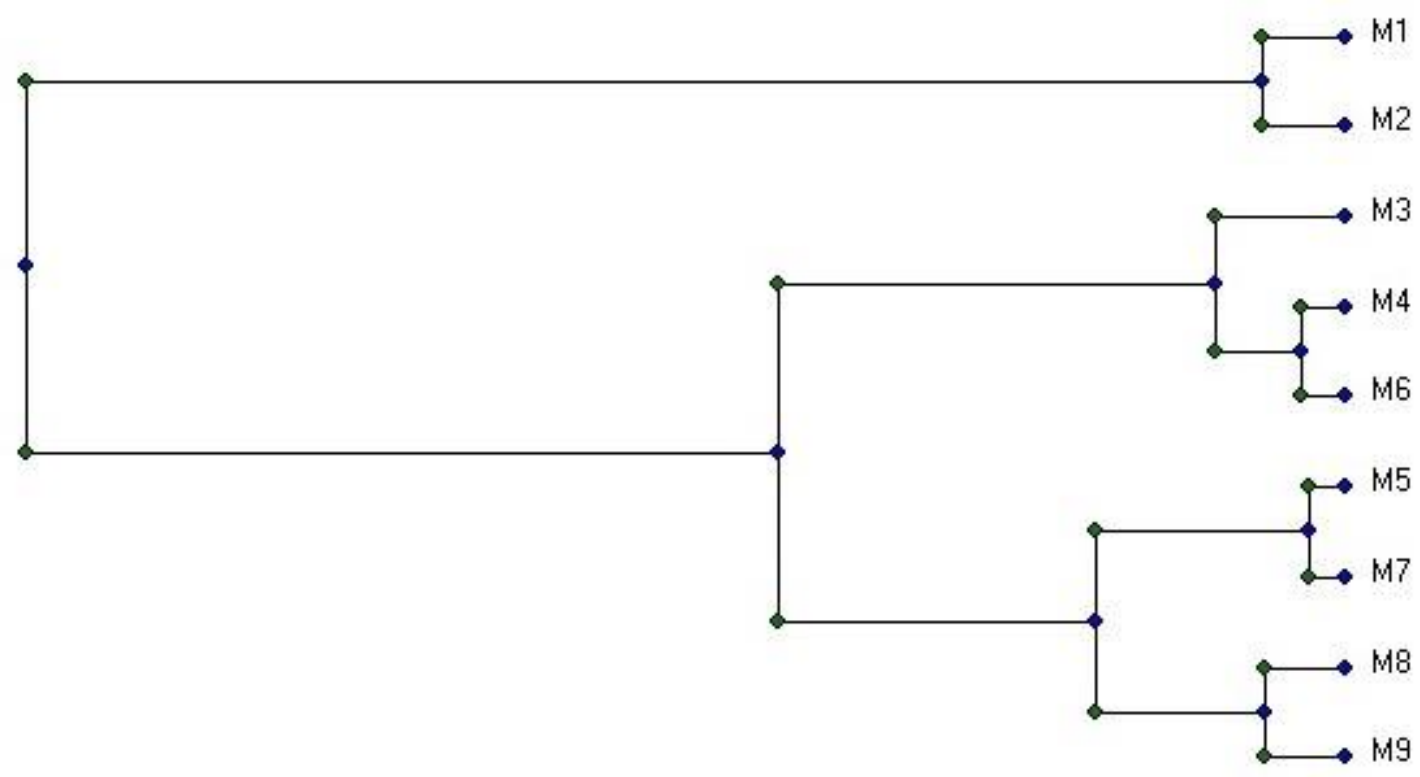

Plate 2. Dendogram from morphological data from field data collected from Populus species surveyed at four governorates of Egypt.

Abbreviations: M1: $P$. euramericana female Giza, M2: $P$. euramericana male Giza, M3: $P$. deltoides Giza, M4: P. nigra Cairo, M5: P. nigra Gharbia, M6: P. deltoides Gharbia, M7: $P$. alba Gharbia, M8: $P$. euramericana female Gharbia, and M9: P. nigra Qaliobia.

\section{Genetic discrimination analysis}

Initially, six ISSR primers were screened for polymorphism and based on the clear scorable band pattern, three primers (17899A, 17899B and HB13) were selected for DNA analysis of the species and were of good quality (Plates 3, 5 and 7). These primers produced polymorphic, as well as, monomorphic bands when applied to the Poplar species understudied. A total number of 34 bands resulted from these primers. 13 bands with 17899A, 12 bands with 17899B and 9 bands with HB13 primer. The total number of polymorphic bands resulted from the three ISSR primers were 21 bands. These bands resulted in the total polymorphism percentage of $67.52 \%$. The data for each primer were shown with dendograms in Plates (4, 6 and 8) for 17899A, 17899B and HB13 respectively, and illustrated in Tables (4, 5 and 6) respectively.

Climatic differences both affected the genetic content of the Populus species beside their original genetic structure and this was reflected on the plant behavior (both morphologically and physio- logically) (Table 7). For instance, there were 8 Unique bands apparent. Three unique bands for 17899A primer: 832 and 472 bp for $P$. nigra from Cairo and 277 bp for $P$. alba. Two unique bands with 17899B primer: 570,441 and 212 bp with $P$. alba from Gharbia. Three unique bands with HB13 primer: 985 and 936 bp with $P$. alba from Gharbia and 486 with $P$. nigra Gharbia. So, $P$. alba from Gharbia was the most affected one with this variation.

The similarity coefficient values ranged from 0.342 to 0.723 using dice coefficient (Table 8); showed a close relationship between M1 ( $P$. euramericana Female Giza) and M8 ( $P$. euramericana Female Gharbia) (0.723) and least genetic similarity between M6 ( $P$. deltoides Gharbia) and M7 ( $P$. alba Gharbia) (0.342). The genetic relationships among poplar species distributed in Egypt were analyzed by UPGMA method (Plate 9). The dendrogram separated the poplar into two major groups genetic distance 0.48 . In addition, the combination between genetic and morphological characteristics resulted in a clear relation among surveyed species (Plate 10). 


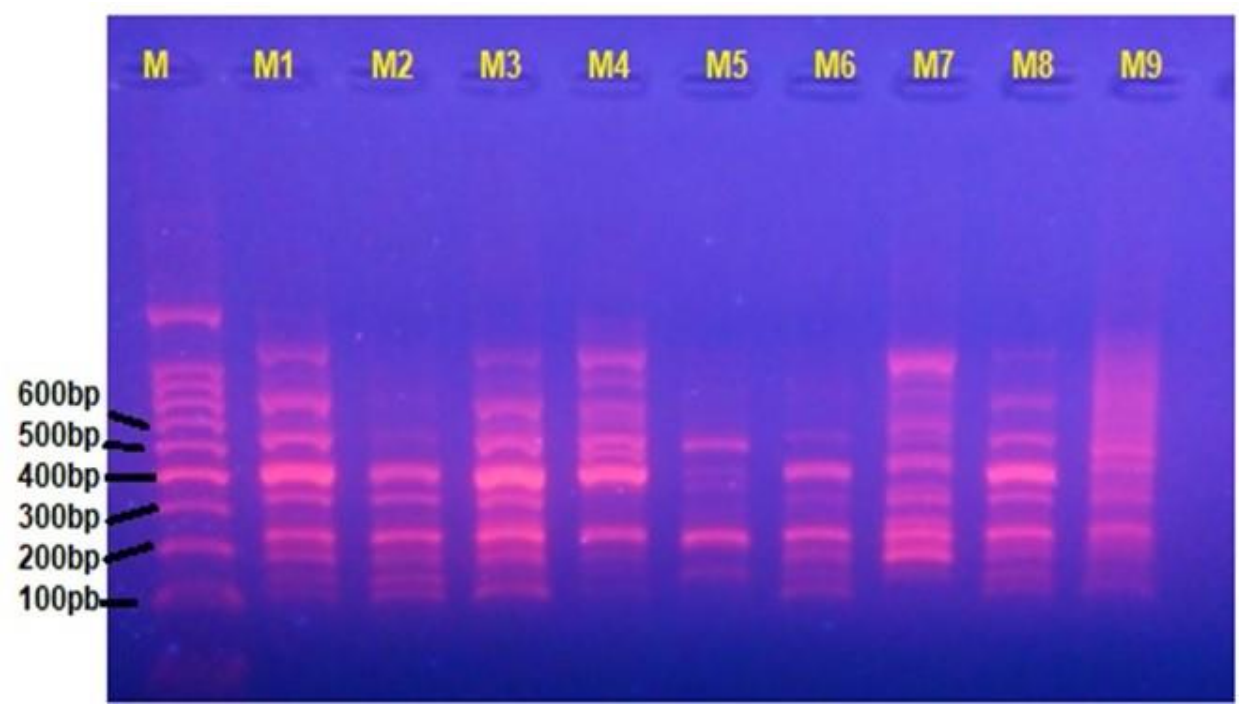

Plate 3. Gel electrophoresis of band patterns obtained from 17899A primer applied to nine samples collected samples of Populus species surveyed at four governorates of Egypt.

Abbreviations: M1: $P$. euramericana female Giza, M2: $P$. euramericana male Giza, M3: $P$. deltoides Giza, M4: P. nigra Cairo, M5: P. nigra Gharbia, M6: P. deltoides Gharbia, M7: $P$. alba Gharbia, M8: $P$. euramericana female Gharbia, and M9: P. nigra Qaliobia.

Table 4. Data analysis of band patterns of 17899A primer applied to nine samples of Populus plant species understudied at four governorates of Egypt.

\begin{tabular}{|c|c|c|c|c|c|c|c|c|c|c|c|}
\hline Band no. & Mwt. (bp) & M1 & M2 & M3 & M4 & M5 & M6 & M7 & M8 & M9 & $\begin{array}{c}\text { Band } \\
\text { type }\end{array}$ \\
\hline 1 & 923.182 & 1 & 0 & 1 & 1 & 0 & 0 & 1 & 1 & 0 & $\mathrm{P}$ \\
2 & 832.033 & 0 & 0 & 0 & 1 & 0 & 0 & 0 & 0 & 0 & $U$ \\
3 & 700.000 & 1 & 0 & 0 & 0 & 0 & 0 & 0 & 1 & 0 & $\mathrm{P}$ \\
4 & 658.141 & 0 & 0 & 1 & 1 & 0 & 0 & 0 & 0 & 0 & $\mathrm{P}$ \\
5 & 523.318 & 1 & 1 & 1 & 1 & 1 & 1 & 1 & 1 & 1 & $\mathrm{M}$ \\
6 & 472.871 & 0 & 0 & 0 & 1 & 0 & 0 & 0 & 0 & 0 & $\mathrm{U}$ \\
7 & 405.618 & 1 & 1 & 1 & 1 & 1 & 1 & 1 & 1 & 1 & $\mathrm{M}$ \\
8 & 326.489 & 1 & 1 & 1 & 0 & 0 & 1 & 1 & 1 & 1 & $\mathrm{P}$ \\
9 & 277.703 & 0 & 0 & 0 & 0 & 0 & 0 & 1 & 0 & 0 & $\mathrm{U}$ \\
10 & 224.565 & 1 & 1 & 1 & 1 & 1 & 1 & 1 & 1 & 1 & $\mathrm{M}$ \\
11 & 170.850 & 1 & 1 & 1 & 1 & 1 & 1 & 1 & 1 & 1 & $\mathrm{M}$ \\
12 & 113.431 & 0 & 1 & 0 & 0 & 0 & 1 & 0 & 0 & 0 & $\mathrm{P}$ \\
13 & 88.159 & 0 & 1 & 1 & 0 & 0 & 0 & 0 & 0 & 0 & $\mathrm{P}$ \\
\hline
\end{tabular}

Abbreviations: M1: $P$. euramericana female Giza, M2: $P$. euramericana male Giza, M3: $P$. deltoides Giza, M4: $P$. nigra Cairo, M5: $P$. nigra Gharbia, M6: $P$. deltoides Gharbia, M7: $P$. alba Gharbia, M8: $P$. euramericana female Gharbia, and M9: P. nigra Qaliobia. 


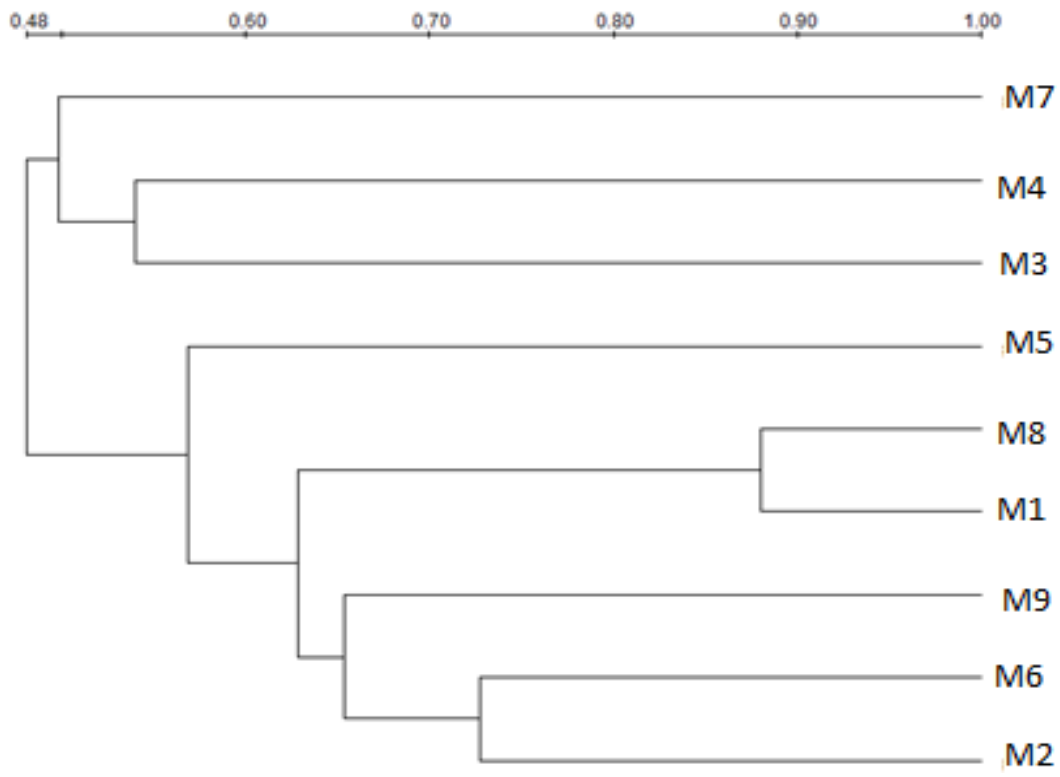

Plate 6. Dendogram for the differences among Populus species data surveyed at four governorates of Egypt according to the use of 17899A primer.

Abbreviations: M1: $P$. euramericana female Giza, M2: $P$. euramericana male Giza, M3: $P$. deltoides Giza, M4: P. nigra Cairo, M5: P. nigra Gharbia, M6: P. deltoides Gharbia, M7: $P$. alba Gharbia, M8: $P$. euramericana female Gharbia, and M9: P. nigra Qaliobia.

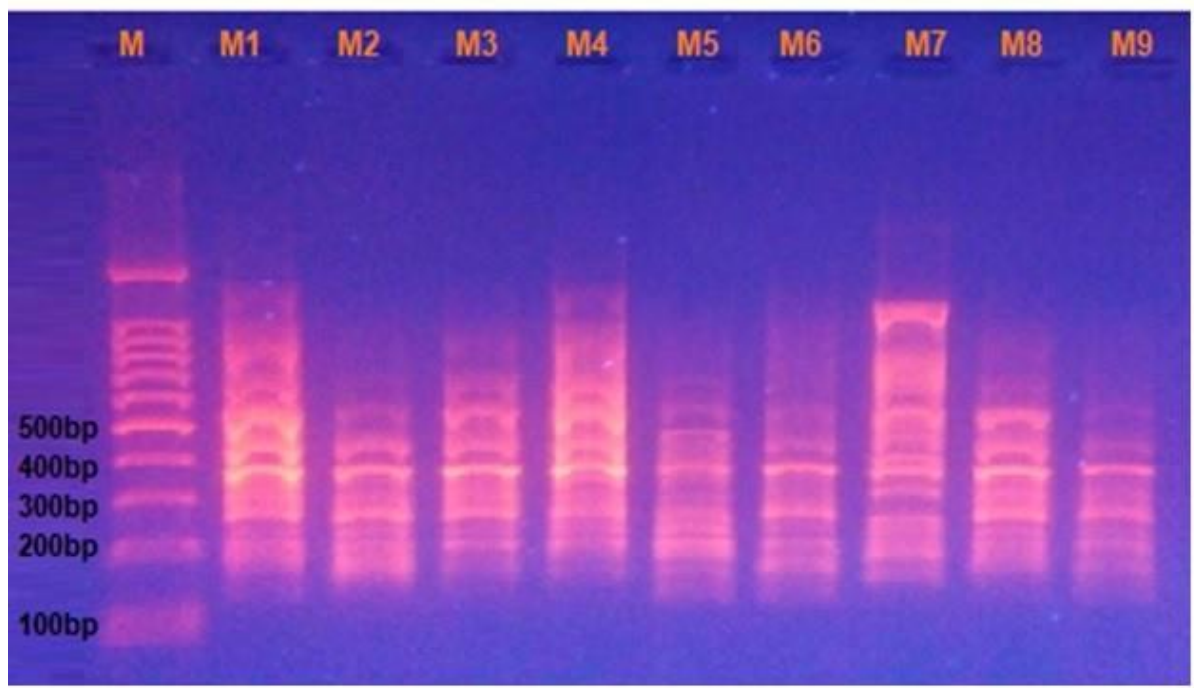

Plate 5. Gel electrophoresis of band pattern obtained from 17899B primer with collected samples of Populus species surveyed at four governorates of Egypt.

Abbreviations: M1: $P$. euramericana female Giza, M2: $P$. euramericana male Giza, M3: $P$. deltoides Giza, M4: $P$. nigra Cairo, M5: $P$. nigra Gharbia, M6: $P$. deltoides Gharbia, M7: $P$. alba Gharbia, M8: $P$. euramericana female Gharbia, and M9: P. nigra Qaliobia. 
Table 5. Data analysis of band pattern of 17899B primer applied to nine samples of Populus plant species understudied at four governorates of Egypt.

\begin{tabular}{|c|c|c|c|c|c|c|c|c|c|c|c|}
\hline Band no. & Mwt. (bp) & M1 & M2 & M3 & M4 & M5 & M6 & M7 & M8 & M9 & $\begin{array}{c}\text { Band } \\
\text { type }\end{array}$ \\
\hline 1 & 700.000 & 1 & 0 & 1 & 1 & 0 & 0 & 1 & 0 & 0 & $\mathrm{P}$ \\
2 & 570.895 & 0 & 0 & 0 & 0 & 0 & 0 & 1 & 0 & 0 & $\mathrm{U}$ \\
3 & 516.852 & 1 & 0 & 1 & 1 & 1 & 0 & 0 & 0 & 0 & $\mathrm{P}$ \\
4 & 441.020 & 0 & 0 & 0 & 0 & 0 & 0 & 1 & 0 & 0 & $\mathrm{U}$ \\
5 & 411.314 & 1 & 1 & 1 & 1 & 1 & 1 & 1 & 1 & 1 & $\mathrm{M}$ \\
6 & 330.193 & 1 & 1 & 1 & 1 & 1 & 1 & 1 & 1 & 1 & $\mathrm{M}$ \\
7 & 265.640 & 1 & 1 & 1 & 1 & 1 & 1 & 1 & 1 & 1 & $\mathrm{M}$ \\
8 & 212.542 & 0 & 0 & 0 & 0 & 0 & 0 & 1 & 0 & 0 & $\mathrm{U}$ \\
9 & 169.349 & 1 & 1 & 1 & 1 & 1 & 1 & 1 & 1 & 1 & $\mathrm{M}$ \\
10 & 102.811 & 0 & 1 & 0 & 0 & 1 & 0 & 1 & 1 & 1 & $\mathrm{P}$ \\
11 & 87.055 & 1 & 1 & 1 & 1 & 1 & 1 & 0 & 1 & 0 & $\mathrm{P}$ \\
12 & 80.107 & 0 & 0 & 0 & 1 & 0 & 1 & 1 & 1 & 1 & $\mathrm{P}$ \\
\hline
\end{tabular}

Abbreviations: M1: $P$. euramericana female Giza, M2: $P$. euramericana male Giza, M3: $P$. deltoides Giza, M4: $P$. nigra Cairo, M5: P. nigra Gharbia, M6: P. deltoides Gharbia, M7: P. alba Gharbia, M8: $P$. euramericana female Gharbia, and M9: $P$. nigra Qaliobia.

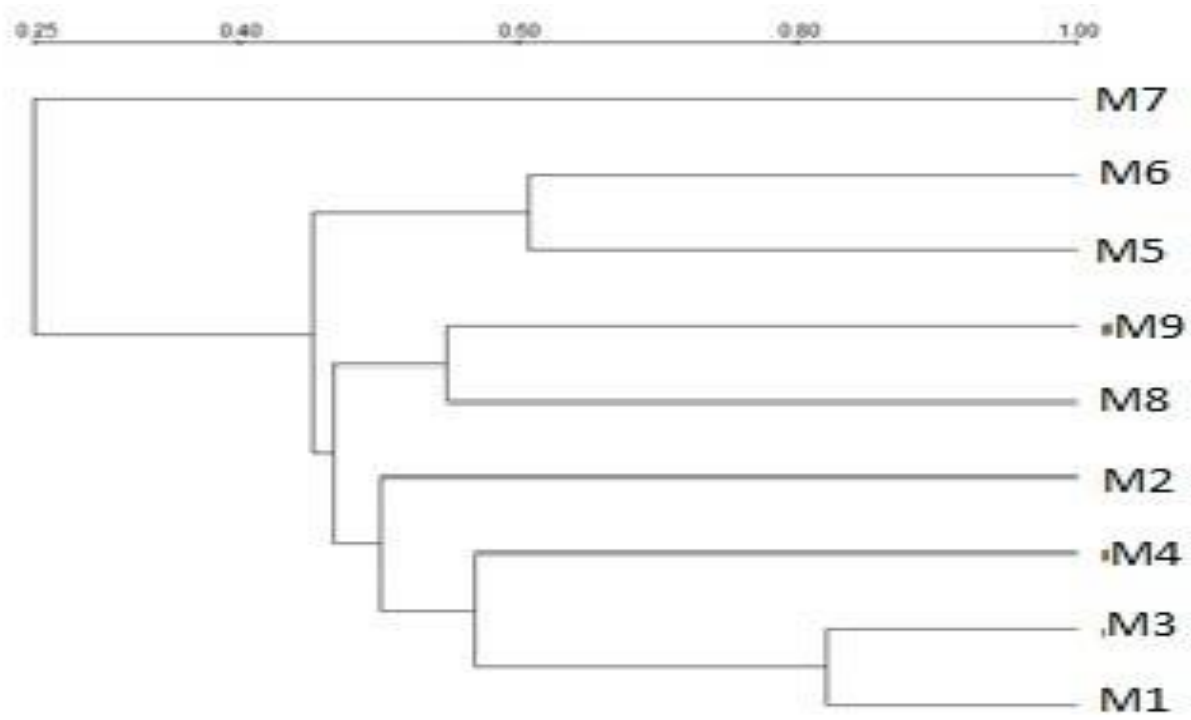

Plate 8. Dendogram for the differences among Populus species data surveyed at four governerates of Egypt according to the use of 17899B primer.

Abbreviations: M1: $P$. euramericana female Giza, M2: $P$. euramericana male Giza, M3: $P$. deltoides Giza, M4: $P$. nigra Cairo, M5: $P$. nigra Gharbia, M6: $P$. deltoides Gharbia, M7: $P$. alba Gharbia, M8: $P$. euramericana female Gharbia, and M9: $P$. nigra Qaliobia. 


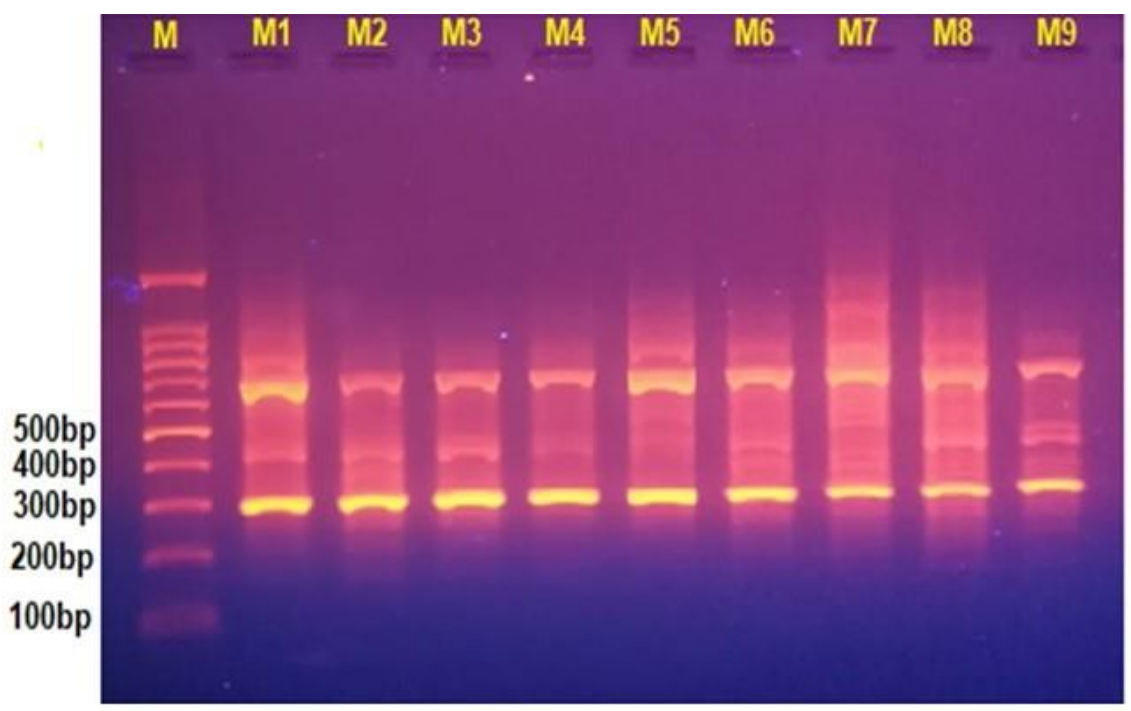

Plate 7. Gel electrophoresis of band pattern obtained from HB13 primer with collected samples of Populus species surveyed at four governorates of Egypt.

Abbreviations: M1: $P$. euramericana female Giza, M2: $P$. euramericana male Giza, M3: $P$. deltoides Giza, M4: P. nigra Cairo, M5: P. nigra Gharbia, M6: P. deltoides Gharbia, M7: $P$. alba Gharbia, M8: $P$. euramericana female Gharbia, and M9: $P$. nigra Qaliobia.

Table 6. Data analysis of band pattern of HB13 primer applied to nine samples of Populus plant species understudied at four governorates of Egypt.

\begin{tabular}{|c|c|c|c|c|c|c|c|c|c|c|c|}
\hline Band no. & Mwt. (bp) & M1 & M2 & M3 & M4 & M5 & M6 & M7 & M8 & M9 & $\begin{array}{c}\text { Band } \\
\text { type }\end{array}$ \\
\hline 1 & 985.573 & 0 & 0 & 0 & 0 & 0 & 0 & 1 & 0 & 0 & $\mathrm{U}$ \\
2 & 936.696 & 0 & 0 & 0 & 0 & 0 & 0 & 1 & 0 & 0 & $\mathrm{U}$ \\
3 & 789.388 & 0 & 1 & 0 & 0 & 1 & 1 & 0 & 0 & 0 & $\mathrm{P}$ \\
4 & 709.410 & 1 & 1 & 0 & 0 & 0 & 1 & 0 & 0 & 0 & $\mathrm{P}$ \\
5 & 559.367 & 1 & 1 & 1 & 1 & 1 & 1 & 1 & 1 & 1 & $\mathrm{M}$ \\
6 & 486.246 & 0 & 0 & 0 & 0 & 1 & 0 & 0 & 0 & 0 & $\mathrm{U}$ \\
7 & 434.912 & 0 & 0 & 0 & 0 & 0 & 0 & 1 & 0 & 1 & $\mathrm{P}$ \\
9 & 330.193 & 1 & 1 & 1 & 1 & 1 & 1 & 1 & 1 & 1 & $\mathrm{M}$ \\
9 & 200.000 & 1 & 1 & 1 & 1 & 1 & 1 & 1 & 1 & 1 & $\mathrm{M}$ \\
\hline
\end{tabular}

Abbreviations: M1: $P$. euramericana female Giza, M2: $P$. euramericana male Giza, M3: $P$. deltoides Giza, M4: $P$. nigra Cairo, M5: P. nigra Gharbia, M6: $P$. deltoides Gharbia, M7: $P$. alba Gharbia, M8: $P$. euramericana female Gharbia, and M9: P. nigra Qaliobia. 


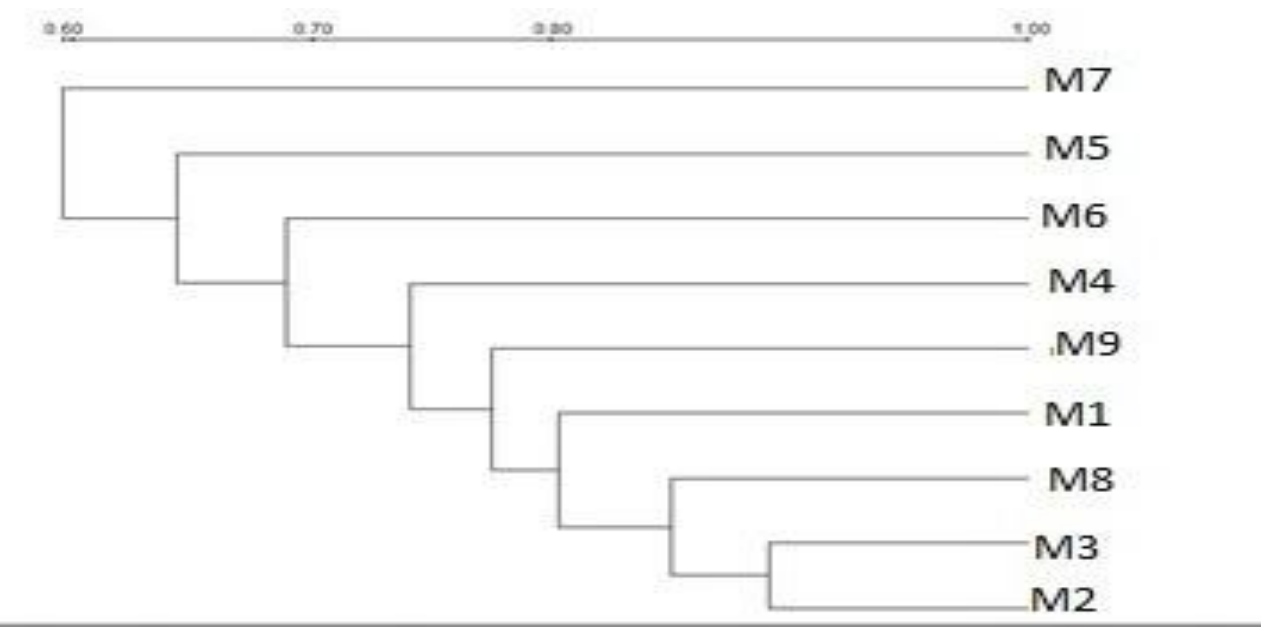

Plate 10. Dendogram for the differences among Populus species data surveyed at four governerates of Egypt according to the use of HB13 primer.

Abbreviations: M1: $P$. euramericana female Giza, M2: $P$. euramericana male Giza, M3: $P$. deltoides Giza, M4: $P$. nigra Cairo, M5: $P$. nigra Gharbia, M6: $P$. deltoides Gharbia, M7: $P$. alba Gharbia, M8: $P$. euramericana female Gharbia, and M9: $P$. nigra Qaliobia.

Table 7. List of primers name (ID), their nucleotide sequences and polymorphism percentage used in the ISSR analysis of nine different treatments of Populus subjected to genetic analysis.

\begin{tabular}{|c|c|c|c|c|}
\hline \multirow{2}{*}{ No } & \multirow{2}{*}{ Primer name } & \multicolumn{3}{|c|}{ Populus treatments } \\
\hline & & Total bands & Polymorphic bands & Polymorphism \% \\
\hline 1 & 17899A & 13 & 9 & 69.23 \\
\hline 2 & 17899B & 12 & 8 & 66.67 \\
\hline 3 & HB13 & 9 & 6 & 66.67 \\
\hline \multicolumn{2}{|r|}{ Total } & 34 & 21 & 67.52 \\
\hline
\end{tabular}

Table 8. Total similarity matrix amongst nine different treatments of Populus subjected to genetic discrimination analysis.

\begin{tabular}{|c|c|c|c|c|c|c|c|c|c|}
\hline Samples & M1 & M2 & M3 & M4 & M5 & M6 & M7 & M8 & M9 \\
\hline M1 & 100 & 66.7 & 71.8 & 62.5 & 53.0 & 57.3 & 46.3 & 72.3 & 55.8 \\
M2 & 66.7 & 100 & 64.4 & 55.3 & 57.1 & 61.2 & 43.2 & 65.0 & 55.7 \\
M3 & 71.8 & 64.4 & 100 & 64.7 & 51.4 & 55.3 & 42.6 & 64.4 & 56.0 \\
M4 & 62.5 & 55.3 & 64.7 & 100 & 50.9 & 53.8 & 45.9 & 59.6 & 50.7 \\
M5 & 53.0 & 57.1 & 51.4 & 50.9 & 100 & 61.3 & 34.2 & 56.3 & 56.4 \\
M6 & 57.3 & 61.2 & 55.3 & 53.8 & 61.3 & 100 & 47.0 & 62.4 & 66.3 \\
M7 & 46.3 & 43.2 & 42.6 & 45.9 & 34.2 & 47.0 & 100 & 46.9 & 45.5 \\
M8 & 72.3 & 65.0 & 64.4 & 59.6 & 56.3 & 62.4 & 46.9 & 100 & 66.3 \\
M9 & 55.8 & 55.7 & 56.0 & 50.7 & 56.4 & 66.3 & 45.5 & 66.3 & 100 \\
\hline
\end{tabular}

Abbreviations: M1: $P$. euramericana female Giza, M2: $P$. euramericana male Giza, M3: $P$. deltoides Giza, M4: P. nigra Cairo, M5: P. nigra Gharbia, M6: P. deltoides Gharbia, M7: P. alba Gharbia, M8: $P$. euramericana female Gharbia, and M9: $P$. nigra Qaliobia. 


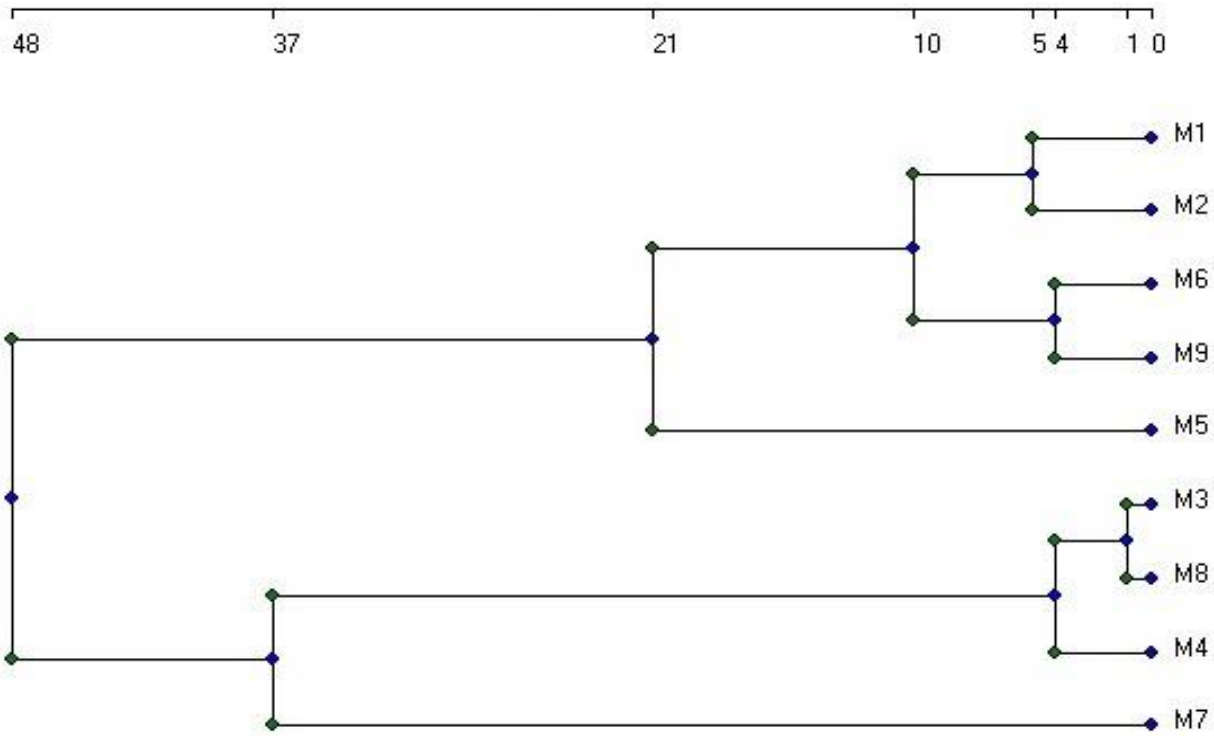

Plate 9. Neighbor-joining clustering trees constructed from amplified fragment length polymorphism genetic using three different primers data of field collection of Populus species.

Abbreviations: M1: $P$. euramericana female Giza, M2: $P$. euramericana male Giza, M3: $P$. deltoides Giza, M4: $P$. nigra Cairo, M5: $P$. nigra Gharbia, M6: $P$. deltoides Gharbia, M7: $P$. alba Gharbia, M8: $P$. euramericana female Gharbia, and M9: P. nigra Qaliobia.

\begin{tabular}{lllll}
\hline $3.97 \mathrm{E} 4$ & $1.71 \mathrm{E} 4$ & $7.52 \mathrm{E} 3$ & $3.952 .41 .10 \mathrm{E} 3$
\end{tabular}

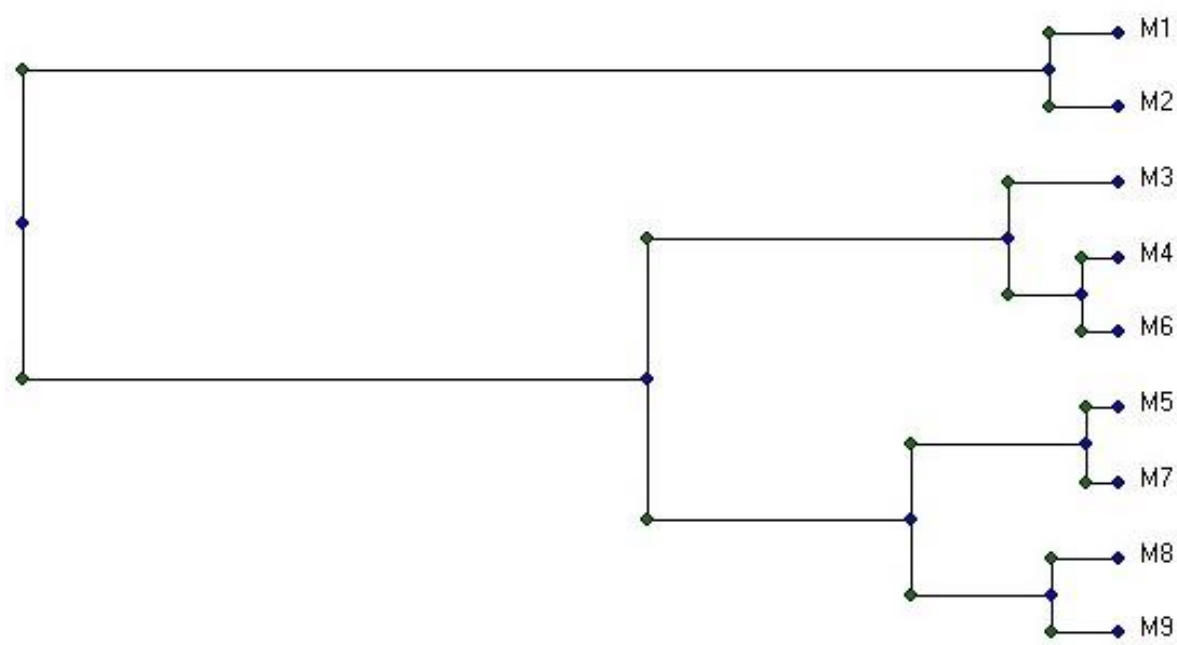

Plate 10. Neighbor-joining clustering trees constructed from morphological and amplified fragment length polymorphism genetic data of field collection of Populus species.

Abbreviations: M1: $P$. euramericana female Giza, M2: $P$. euramericana male Giza, M3: $P$. deltoides Giza, M4: $P$. nigra Cairo, M5: $P$. nigra Gharbia, M6: $P$. deltoides Gharbia, M7: $P$. alba Gharbia, M8: $P$. euramericana female Gharbia, and M9: $P$. nigra Qaliobia. 


\section{DISCUSSION}

The survey trial in this research study was restricted to types of Populus, i.e. identifying species only and not to count up numbers of trees in the four Governorates involved, namely Giza, Cairo, Qaliobia and Gharbia. Survey data assembled was only restricted to information from research stations belonging to ARC (Ministry of Agriculture) located inside the four governorates. In Cairo and Qaliobia governorates, P. nigra was the only existed species. Whereas, in Giza, three species were found, viz. $P$. euramericana female, $P$. euramericana male and $P$. deltoides. Meanwhile, $P$. nigra, $P$. deltoides, $P$. alba and $P$. euramericana female existed in Gharbia governorate.

Exotic plants like maple trees, were found to introduce new morphological and biometric adaptation when they inhibit new sites (Lamarque et al 2015)). In this research study with Populus, this proved absolutely valid when $\mathrm{DBH}$ is used to discriminate among species, $P$. deltoides and $P$. euramericana female Giza and $P$. deltoides from Gharbia gave the largest DBH with noticed lower values were obtained from $P$. euramericana female in Gharbia and $P$. nigra in Qaliobia. Beside number of branches for $P$. euramericana female from Giza and $P$. nigra from Cairo demonstrated higher number. Whereas, $P$. euramericana female showed the lowest number of branches (3 branches).

All introduced Populus species showed high adaptation level to Egyptian territory across 4 different governorates. These findings suggest that phenotypic plasticity and genetic differentiation act synergistically to provide introduced tree populations substantial potential for rapid adaptation to new environmental conditions. Similar result was obtained by Lamarque et al (2015) showing the ability of exotic plants for adaptation. Thus, Egyptian environment is proper for woody species as well as some native woody plants from the flora.

LA plays an important aspect in research with regards to plant physiology in agriculture and dendrology (Broadhead et al 2003). Specifically, LA is involved in photosynthesis, transpiration, light interception, biomass estimation and water balance (Kucharik et al 1998). Leaf structure, LA and leaf shape vary tremendously between and within species as well as in response to environmental conditions, and these variations are known to play a key role in shaping plant functioning (Nicotra et al 2011, Niinemets 2015).

Results obtained here showed a variation amongst Populus species surveyed, both female and male of $P$. euramericana from Giza were superior in their LA. Whereas, the smallest LA was found in $P$. alba from Gharbia. Also, $P$. nigra was variate among surveyed sites where there was a significant difference between $L A$ values. The huge increase of variation observed for LA indicates that the contrast among Populus species. The plant physiologists, biologists and agronomists have demonstrated the importance of LA in the growth analysis, the estimation of potential biological and agronomic yield, basis of the efficient use of solar radiation and mineral nutrition (Sonnentag et al 2007). Nevertheless, Guet et al (2015) showed within $P$. nigra nine population presence of various substantial variation and leaf trait plasticity. Leaf nitrogen showed the greatest divergence among populus population and previously found by Bradshaw and Stettler (1995).

Significant Genotype × Environment $(G \times E)$ under variable soil water availability and temperature has also been documented, with examples in the genera Eucalyptus (Dutkowski and Potts 2012), Pinus (Cregg and Zhang, 2001), and Populus (Cochard et al 2007), Populus nigra Fabbrini et al (2012). Similarly here, variations in morphological traits were found within $P$. nigra and $P$. euramericana in various site as well as among all species.

Results of ISSR patterns scored eight unique bands distinguishable species-specific bands for poplar, which could be used as molecular markers for poplar cultivated in Egypt. Several authors reported on the usefulness of ISSR for cultivar or species identifications. The similarity coefficient values and the UPGMA dendrogram revealed narrow genetic base among the tested species. This is likely due to the fact that their parental breeding lines used to develop these species were the same or were very close to each other. Expected diversity can be found even at small scale forest plantation as well as in our result of inhabitant Populus species. Similarly, variations in genetic traits were found within each of $P$. nigra and $P$. euramericana in sites surveyed. The consistent clustering derived from both phenotypic and genotypic data herewith proves the high diversity among surveyed Populus species.

Our research study suggest that Populus species possess genetic variation and can adapt to new environmental conditions, which in its selfvaluable information would potentially lead to promising applications. Further assessment may be required on the flowering behaviors, leaf fall and flushing periodicity which could be tried on 
various poplar species that exist in Egyptian territories. Furthermore, tolerance of species and control to abiotic and biotic stress should be monitored under Egyptian territory condition.

\section{REFERENCES}

Bandyopadhyay S. and Raychaudhuri S.S. 2013. Development and comparison of RAPD, SCAR and AFLP markers for distinguishing some medicinally important species of the genus Phyllanthus. Plant Biosystems-An Int. J. Dealing with all Aspects of Plant Biology, 147(1), 12-20.

Benesty J., Chen J., Huang Y. and Cohen I. 2009. Pearson correlation coefficient. In Noise reduction in speech processing, Springer, Berlin, Heidelberg. pp. 1-4.

Benomar L., Des Rochers A. and Larocque G.R., 2011. Changes in specific leaf area and photosynthetic nitrogen-use efficiency associated with physiological acclimation of two hybrid poplar clones to intraclonal competition. Can. J. For Res., 41, 1465-1476.

Bradshaw H.D. and Jr. Stettler R.F. 1995. Molecular genetics of growth and development in Populus. IV. Mapping QTLs with large effects on growth, form, and phenology traits in a forest tree. Genetics, 139, 963-973.

Broadhead J.S., Muxworthy A.R., Ong C.K. and Black C.R. 2003. Comparison of methods for determining leaf area in tree rows. Agric. and Forest Meteorology, 115(3-4), 151-161.

Cagelli L. and Lefevre F. 1995. The Conservation of Populus nigra L. and gene flow with cultivated poplars in Europe. Forest genetics, 2(3), 135-144.

Cochard H., Casella E. and Mencuccini M. 2007. Xylem vulnerability to cavitation varies among poplar and willow clones and correlates with yield. Tree Physiology, 27, 1761-1767.

Cregg B.M. and Zhang J.W. 2001. Physiology and morphology of Pinus sylvestris seedlings from diverse sources under cyclic drought stress. Forest Ecology and Management, 154, 131-139.

David D.J. 1959. Determination of calcium in plant material by atomic-absorption spectrophotometry. Analyst, 84, 536-545.

Doyle J.J. and Doyle J.L. 1990. Isolation of plant DNA from fresh tissue. Focus, 12(13), 39-40.

Duncan D.B. 1955. Multiple range and multiple $F$ tests. Biometrics, 11(1), 1-42.
Dutkowski G.W. and Potts B.M. 2012. Genetic variation in the susceptibility of Eucalyptus globulus to drought damage. Tree Genetics \& Genomes 8, 757-773.

Edwards K., Johnstone C. and Thompson C. 1991. A simple and rapid method for the preparation of plant genomic DNA for PCR analysis. Nucleic Acids Research, 19(6), 1349.

Fabbrini F., Gaudet M., Bastien C., Zaina G., Harfouche A., Beritognolo I., Marron N., Morgante M., Scarascia-Mugnozza G. and Sabatti M. 2012. Phenotypic plasticity, QTL mapping and genomic characterization of bud set in black poplar. BMC Plant Biology, 12(1), 47.

Feng Y.L., Li Y.P., Wang R.F., Callaway R.M. and Valiente-Banuet A. 2011. A quicker return energy-use strategy by populations of a subtropical invader in the non-native range: a potential mechanism for the evolution of increased competitive ability. J. of Ecology, 99(5), 1116-1123.

Guet J., Fabbrini F., Fichot R., Sabatti M., Bastien C. and Brignolas F. 2015. Genetic variation for leaf morphology, leaf structure and leaf carbon isotope discrimination in European populations of black poplar (Populus nigra L.). Tree Physiology 35, 850-863.

Haber E. and Network A. 1997. Guide to monitoring exotic and invasive plants. Environment Canada. Ottawa, ON, Canada, 49 p.

Isebrands J.G. and Richardson J. 2000. $21^{\text {st }}$ Session of the International Poplar Commission (IPC-2000): poplar and willow culture: meeting the needs of society and the environment; 200 September 24-28; Vancouver, WA. General Technical Report NC-215. St. Paul, MN: US Dept. of Agriculture, Forest Service, North Central Forest Experiment Station, 215 p.

Jackson M.L. 1958. Soil Chemical Analysis. Prentice-Hall. Englewood Cliffs, N.J., USA, 498 p.

Kucharik C.J., Norman J.M. and Gower S.T. 1998. Measurements of branch area and adjusting leaf area index indirect measurements. Agri. and Forest Meteorology, 91(1-2), 69-88.

Lamarque L.J., Lortie C.J., Porté A.J. and Delzon S. 2015. Genetic differentiation and phenotypic plasticity in life-history traits between native and introduced populations of invasive maple trees. Biological Invasions, 17(4), 11091122. 
Lefèvre F., Légionnet A., de Vries S. and Turok J. 1998. Strategies for the conservation of a pioneer tree species, Populus nigra L., in Europe. Genetics Selection Evolution, 30(1), S181.

Li A.J., Yang S.F., Li X.Y. and Gu J.D. 2008. Microbial population dynamics during aerobic sludge granulation at different organic loading rates. Water Research, 42(13), 3552-3560.

Meyer W., Mitchell T.G., Freedman E.Z. and Vilgalys R. 1993. Hybridization probes for conventional DNA fingerprinting used as single primers in the polymerase chain reaction to distinguish strains of Cryptococcus neoformans. J. of Clinical Microbiology, 31(9), 2274-2280.

Morandini R. 1964. Genetics and improvement of exotic trees. Unasylva, 18(2-3), 51.

Nicotra A.B., Leigh A., Boyce C.K., Jones C.S., Niklas K.J., Royer D.L. and Tsukaya H. 2011. The evolution and functional significance of leaf shape in the angiosperms. Funct Plant Biol. $38,535-552$.

Niinemets Ü. 2015. Is there a species spectrum within the world-wide leaf economics spectrum? Major variations in leaf functional traits in the Mediterranean sclerophyll Quercus ilex. New Phytol., 205, 79-96.

Piper C.S. 1950. Soil and Plant Analysis. University of Adelaide, Adelaide, Australia, 368 p.
Plummer D.T. 1971. An Introduction to Practical Biochemistry. Published by Mc Graw Hill Book Company Limited, UK, 369 p.

Qiwen Z., Xiaohua S. and Jinhua L. 1999. Genetic Improvement of Poplar in China [J]. Review of China Agric. Sci. and Technology, 2 p.

Rodriguez H.G., Maiti R. and Kumari C.A. 2016. Biodiversity of Leaf Traits in Woody Plant Species in Northeastern Mexico: A Synthesis. For. Res, 5(2), 169.

Schneider C.A., Rasband W.S. and Eliceiri K.W. 2012. NIH Image to ImageJ: 25 years of image analysis. Nature Methods, 9(7), 671-675.

Sonnentag O., Talbot J., Chen J.M. and Roulet N.T. 2007. Using direct and indirect measurements of leaf area index to characterize the shrub canopy in an ombrotrophic peatland. Agric. and Forest Meteorology, 144(3-4), 200-212.

Tuskan G.A., Difazio S., Jansson S., Bohlmann J., Grigoriev I., Hellsten U., Putnam N., Ralph S., Rombauts S., Salamov A. and Schein J. 2006. The genome of black cottonwood, Populus trichocarpa (Torr. \& Gray). Sci., 313(5793), 1596-1604.

Zietkiewicz E., Rafalski A. and Labuda D. 1994. Genome fingerprinting by simple sequence repeats (SSR)-anchored polymerase chain reaction amplification. Genomic, 20, 176-183. 


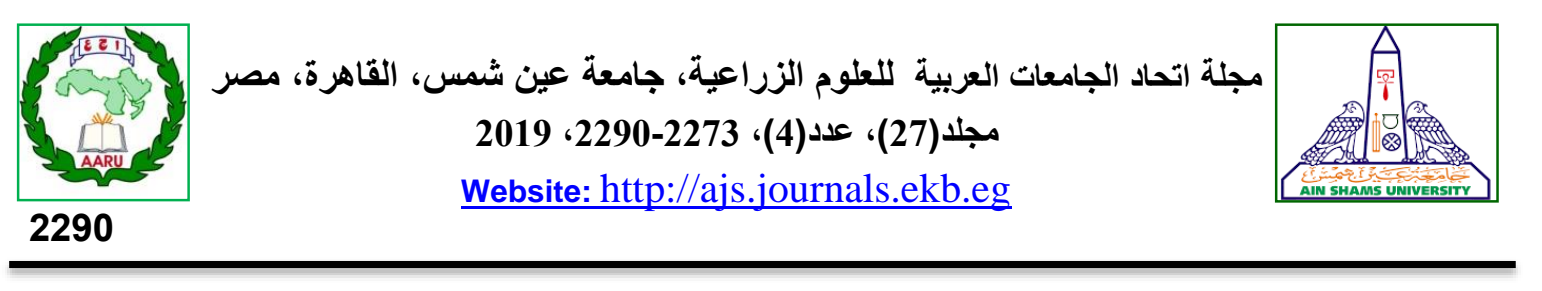

$$
\text { التفرقه بين خمس انواع من الحور من حيث الصفات الظاهريه وإلكيميائية }
$$$$
\text { محمد فتحي أحمد1 - عبدالعزيز محمد حني2 - محمد هويدي 2" - }
$$

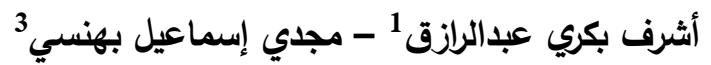

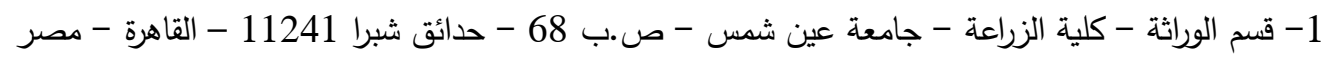

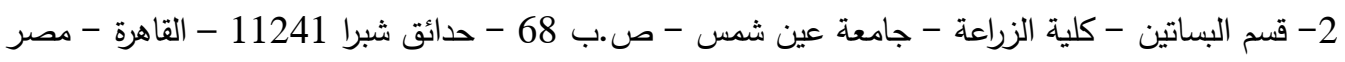

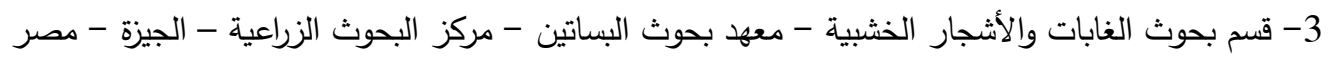

*Corresponding author: mohamed.hewidy@agr.asu.edu.eg

Received 7 October, 2019 Accepted 12 November, 2019

P. nigrag P. albag

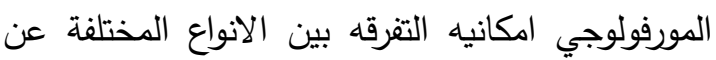

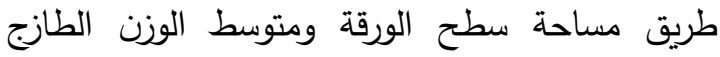
والجاف للأوراق مكتملة النمو. تم كثف التباين الونة الوراثي

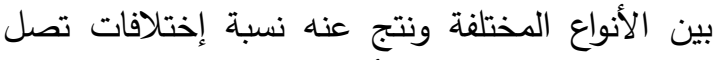
الي 67.52\% بين الأنواع التي تم حصرها من التشات تصل المحافظات المختلفة. - المن

الكلمات الدالة: مصر ، حصر ، أثجار خثبية، الحور، الصفات الظاهرية، التحليل الوراثي، التتابع الداخلي التئي البسيط

[181]

أجريت الدراسة من خلال عمل حصر بمحطات البركة البحوث التابعة لمركز البحوث الزراعية في أربع أربع

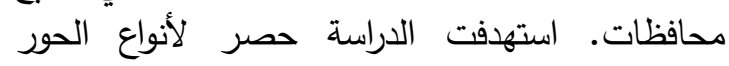
المنزرعة في أربع محافظات داخل جمهورية مصر الاتهر

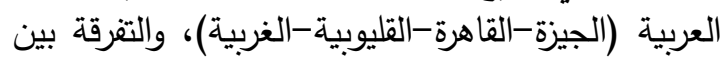

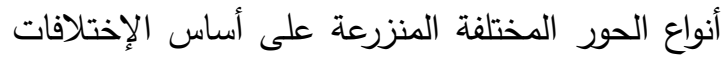

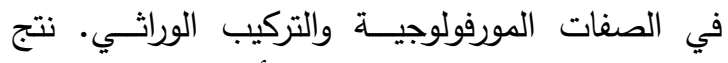

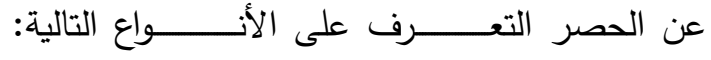
P. euramericana female والغربية و P. euramericana male الجيزة و P. deltoides بحافظة الجيزة والغربيـة 